\title{
To repair or not to repair: Who should undergo tricuspid valve repair at the time of pulmonary valve replacement in previously repaired tetralogy of Fallot
}

\author{
Justin T. Tretter, MD, and Andrew N. Redington, MD
}

From The Heart Institute, Cincinnati Children's Hospital Medical Center, Cincinnati, Ohio.

Disclosures: Authors have nothing to disclose with regard to commercial support.

Received for publication Jan 4, 2017; accepted for publication Jan 12, 2017; available ahead of print Feb 24, 2017.

Address for reprints: Justin T. Tretter, MD, 3333 Burnet Ave, Cincinnati, OH 45229 (E-mail: justin.tretter@ cchmc.org).

J Thorac Cardiovasc Surg 2017;154:224-5

$0022-5223 / \$ 36.00$

Copyright (c) 2017 by The American Association for Thoracic Surgery

http://dx.doi.org/10.1016/j.jtcvs.2017.01.017

We commend Roubertie and colleagues ${ }^{1}$ for their addition to the very limited and conflicting literature exploring the appropriateness of simultaneous tricuspid valve repair (TVR) at the time of pulmonary valve replacement (PVR) in adults with repaired tetralogy of Fallot or "equivalent" congenital heart disease. It is well known that some degree of tricuspid regurgitation (TR) is common in patients who require PVR. Given that the indications for and benefits of PVR itself remain a subject of debate, ${ }^{2}$ however, it is perhaps not surprising that investigators have struggled to show benefits of an additional procedure. Nonetheless, the study of Roubertie and colleagues ${ }^{1}$ gives us an opportunity to review the available data and assess how their article may contribute to current understanding and decision making.

Roubertie and colleagues ${ }^{1}$ report a significant improvement at 1 postoperative year in the degree of TR and functional class in the 8 patients with severe TR who underwent PVR and TVR with a rigid ring compared with their remaining 9 patients with severe TR who underwent PVR alone. There was no benefit in terms of functional class for those undergoing TVR in the presence of moderate TR. ${ }^{1}$ These new data conflict with the results reported by Cramer and colleagues, ${ }^{3}$ who reported outcomes in a similar cohort of patients. Moderate or severe TR was seen in $60 \%$ of their patients, with $50 \%$ of them undergoing TVR, most of these with a rigid ring. Six months postoperatively, there was significant improvement in TR regardless of whether TVR had been performed, suggesting reduced right ventricular volumes and tricuspid valve annular dimensions as the underlying mechanism for TR improvement.

The findings of Cramer and colleagues ${ }^{3}$ are supported by those of Kogon and colleagues. ${ }^{4,5}$ As pointed out by Roubertie and colleagues, ${ }^{1}$ in the study of Kogon and colleagues ${ }^{4}$ there was no benefit of TVR at 1 month in terms of degree of postoperative TR. Roubertie and colleagues ${ }^{1}$ failed, however, to point out that in the study of Kogon

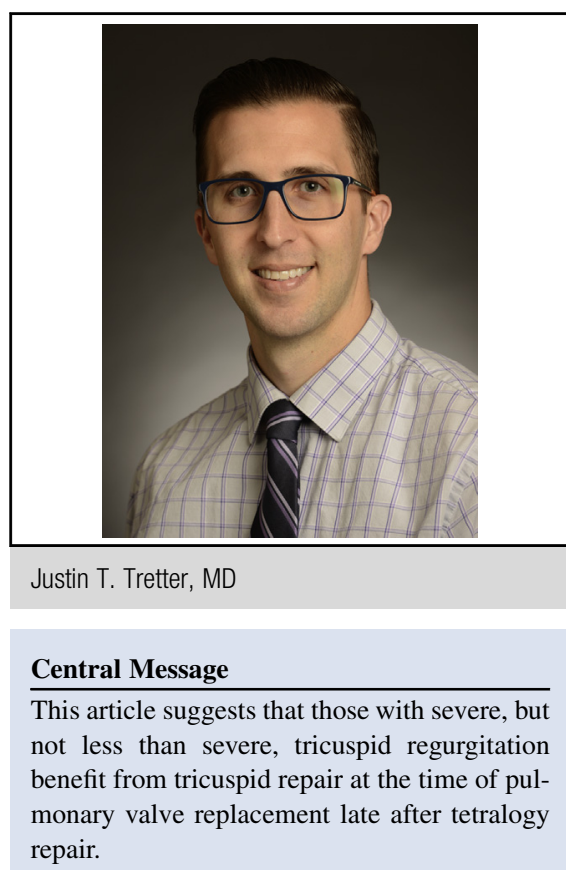

See Article page 214

and colleagues ${ }^{5}$ the degree of TR at an average of 7 years of follow-up was paradoxically worse in those patients who had undergone TVR, although it should be emphasized that in that study the large majority of patients with preoperatively severe TR underwent surgery (potentially skewing the data), and that TVR was performed with a suture annuloplasty technique rather than with a rigid ring.

Nonetheless, these reports seem to cast at least some doubt on the assertion of Roubertie and colleagues ${ }^{1}$ that additional TVR may be beneficial (even if restricted to those with severe preoperative TR). Before we discount their results as idiosyncratic, however, a recent multicenter study from the Netherlands deserves mention. Bokma and colleagues $^{6}$ reported outcomes of more than 150 patients undergoing PVR. Preoperative TR grade was higher and early postoperative TR decrease was greater in those who had undergone concomitant TVR. Furthermore, in patients without TVR, TR grade late after PVR was comparable with preoperative TR grade, whereas TR grade late after PVR remained significantly lower in patients with TVR. 6 
To summarize, we have a hung jury. What is clear is that PVR alone commonly leads to improvement in TR, and for many patients additional TVR seems unnecessary. The question as to whether there may be a threshold of tricuspid annular dilation and TR severity that represents a "point of no return" without TVR remains unanswered. We are going to resist the seemingly inevitable call for a randomized trial in editorial reviews such as ours (as that would likely require a long-term, multicenter study of a uniform surgical approach, with inclusion of many hundreds or perhaps thousands of patients, to address the question adequately), but rather we make a plea for enhanced surgical registries that not only report surgical outcomes but also include detailed preoperative and postoperative phenotyping and that can ultimately be mined to define fully the optimal treatment of this increasingly large population of patients.

\section{References}

1. Roubertie F, Séguéla PE, Jalal Z, Iriart X, Roques X, Kreitmann B, et al. Tricuspic valve repair and pulmonary valve replacement in adults with repaired tetralogy of Fallot. J Thorac Cardiovasc Surg. 2017;154:214-23.

2. Tweddell JS, Simpson P, Li SH, Dunham-Ingle J, Bartz PJ, Earing MG, et al Timing and technique of pulmonary valve replacement in the patient with tetralogy of Fallot. Semin Thorac Cardiovasc Surg Pediatr Card Surg Annu. 2012;15:27-33.

3. Cramer JW, Ginde S, Hill GD, Cohen SB, Bartz PJ, Tweddell JS, et al. Tricuspid repair at pulmonary valve replacement does not alter outcomes in tetralogy of Fallot. Ann Thorac Surg. 2015;99:899-904.

4. Kogon B, Patel M, Leong T, McConnell M, Book W. Management of moderate functional tricuspid valve regurgitation at the time of pulmonary valve replacement: is concomitant tricuspid valve repair necessary? Pediatr Cardiol. 2010; 31:843-8.

5. Kogon B, Mori M, Alsoufi B, Kanter K, Oster M. Leaving moderate tricuspid valve regurgitation alone at the time of pulmonary valve replacement: a worthwhile approach. Ann Thorac Surg. 2015;99:2117-22; discussion 2122-3.

6. Bokma JP, Winter MM, Oosterhof T, Vliegen HW, van Dijk AP, Hazekamp MG et al. Severe tricuspid regurgitation is predictive for adverse events in tetralogy of Fallot. Heart. 2015;101:794-9. 